Case Report

\title{
A Case of Incomplete Removal of Horseshoe Kidney by Laparoscopic Nephrectomy in an Adult Leading to Urinary Leak: An Eye Opener
}

\author{
S. Venkat Ramanan (D), P. Velmurugan (D), A. R. Bhaskar Prakash, \\ Anuj Arora, and LeelaKrishna Karri \\ Department of Urology, Sri Ramachandra Medical College and Research Institute, Chennai, India \\ Correspondence should be addressed to S. Venkat Ramanan; vramanan2001@yahoo.com
}

Received 20 December 2018; Accepted 8 April 2019; Published 2 May 2019

Academic Editor: Apul Goel

Copyright (C) 2019 S. Venkat Ramanan et al. This is an open access article distributed under the Creative Commons Attribution License, which permits unrestricted use, distribution, and reproduction in any medium, provided the original work is properly cited.

Horseshoe kidney is a common congenital fusion anomaly of the kidneys. It poses a challenge to surgeon because of its very variable anatomy in terms of location and lie, fusion, pelvicalyceal system, and the renal vessels. Here we describe a case of laparoscopic nephrectomy in a horseshoe kidney complicated by incomplete removal because of not realizing the lower and medial extent of pelvicalyceal system across midline to the contralateral side leading to persistent urine leak. The relevant anatomy and the necessary precautions to prevent such complication have been discussed.

\section{Case Report}

A 25-year-old man, driver by profession, presented with recurrent episodes of dull aching right flank pain of 6-year duration. The pain was affecting his work. The patient was thin built with a body-mass-index of $20 \mathrm{Kg} / \mathrm{m}^{2}$. The preoperative CT scan revealed a horseshoe kidney (HSK) with the right side involved by ureteropelvic-junction obstruction (UPJO) causing gross hydronephrosis and parenchymal thinning (Figures 1 and 2). The relative renal function was $11 \%$ on DTPA renogram. The left renal moiety was functioning well with a GFR of $71.9 \mathrm{ml} / \mathrm{min}$. The S. Creatinine was 0.9 $\mathrm{mg} \%$. The patient also had a history of epilepsy but there was no identifiable congenital anomaly other than the HSK. The options of right pyeloplasty and right nephrectomy with their pros and cons were discussed with the patient. The patient opted for nephrectomy. A transperitoneal laparoscopic right nephrectomy was done using five ports in the right lateral position. A preliminary retrograde pyelography (RGP) or right ureteric catheterization was not done. The right colon and duodenum were reflected medially to expose the kidney. As expected the right kidney was lying relatively lower and medially than what a normal kidney would be. Other than the main renal artery, the upper and the lower poles were supplied by accessory polar artery each. The upper polar artery itself had a very early branching and the lower polar artery was crossing the UPJ and causing obstruction. There were two right renal veins lying between the main renal artery and the lower polar artery. The right ureter was divided about $4 \mathrm{~cm}$ below the ureteropelvic junction. All the arteries and the veins were clipped with hem-o-lok clips and divided. The kidney was dissected within the Gerota's fascia from the upper pole downwards. The isthmus was mobilized to the extent possible and was divided just to left of inferior vena cava. Body side of the cut edge showed some brisk bleeding. The cut edge was sutured with 2'0 V-Loc sutures over a surgical bolster and hemostasis was secured. The specimen was removed using an endo-bag and a drain was placed. There was no intraoperative complication. The only abnormal event in the postoperative period was a persistent drain output of $100 \mathrm{ml}$ of urine every 24 hours. The drain fluid creatinine was $22 \mathrm{mg} \%$. The postoperative ultrasound examination of the abdomen did not reveal any significant intra-abdominal collection. Left retrograde pyelogram and 


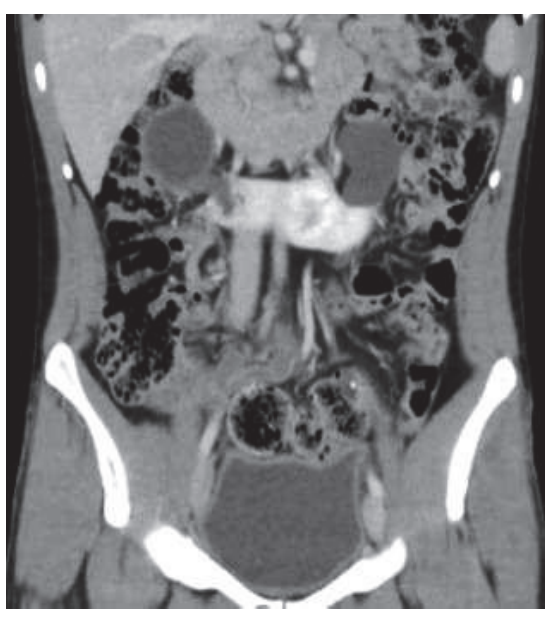

FIGURE 1: Initial preoperative CE-CT scan (coronal section) showing horseshoe kidney with right hydronephrosis.

right retrograde ureterogram done on the 14th postoperative day (POD) did not reveal any contrast leak either from the left side or from the right ureteric stump. Subsequently CT urogram was done which showed that a small residual stump of the right kidney fused to the lower pole of the left kidney was still viable and producing and leaking urine (Figure 3). This stump was supplied by a tiny arterial twig from the left renal artery. An exploratory laparotomy was done on the 16th POD through upper midline incision. The descending colon was reflected medially to expose the lower pole of the left kidney with the attached stump of the right kidney. The stump was densely adherent to the IVC and surrounding structures. For additional exposure and dissection, the mesentery of the transverse colon was opened lateral to the inferior mesenteric vein. The stump was freed from the IVC and delivered to the left side from underneath the inferior mesenteric artery (Figure 4). The stump was divided flush with the lower pole of the left kidney and the cut edge was sutured with 2'0 Vicryl over surgical bolster. The postoperative recovery was uneventful.

\section{Discussion}

Horseshoe kidney is the commonest fusion anomaly of the kidneys and accounts for more than $90 \%$ of it $[1,2]$. The reported incidence based on autopsy and radiographic data is 1:350 to $1: 666$ with a $2: 1$ male predominance [3-7]. HSK differs from crossed fused renal ectopia in that, unlike the latter in which only one kidney moves abnormally across the midline to fuse with the contralateral kidney, in HSK, both of the kidneys migrate abnormally and fuse. In $95 \%$ of cases the kidneys are fused at the lower poles. The lower polar fusion occurs in midline in 40 to $42 \%$ of cases giving rise to $\mathrm{U}$ Shaped HSK or Symmetric HSK (Figure 5). In the remaining $58 \%$ to $60 \%$ of cases the fusion is lateral to the midline with one kidney being more horizontal and extending across the midline to fuse with the lower pole of the more vertical contralateral kidney (asymmetric HSK or L-shaped HSK) [7, 8]. The isthmus is composed of functioning renal parenchyma



FIGURE 2: Initial preoperative CE-CT scan (axial section) showing horseshoe kidney with the fusion of the lower poles to the left of aorta.

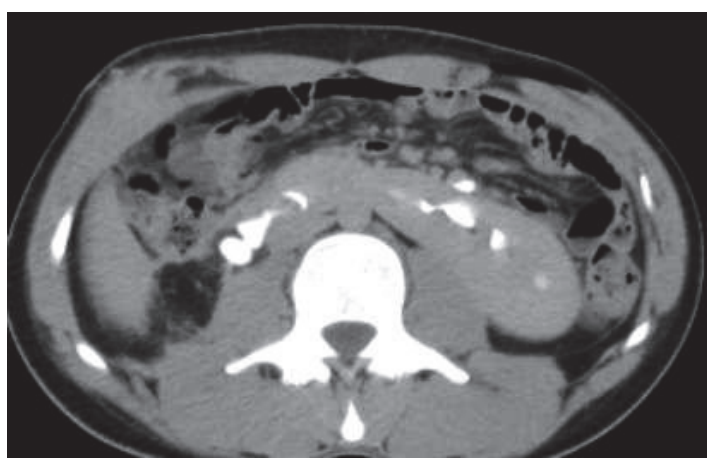

FIGURE 3: CE-CT following laparoscopic right nephrectomy showing leakage of contrast from the residual stump of the right lower pole.



FIGURE 4: Intraoperative picture of exploratory laparotomy showing small residual stump of lower pole of right kidney fused to the lower pole of left kidney. Left ureter is seen running over the lower pole of left kidney.

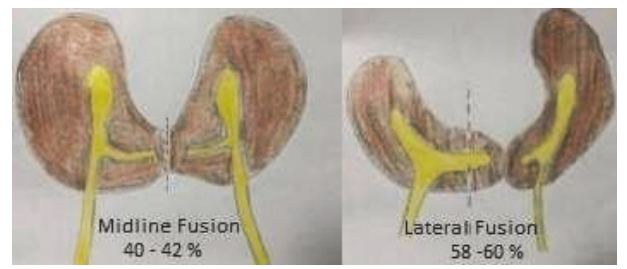

FIGURE 5: Midline lower polar fusion (40 to $42 \%$ ) and lateral lower polar fusion (58\% to $60 \%)$. 
in majority of cases with only $4.4 \%$ to $15 \%$ of HSKs showing a fibrous isthmus $[7,9]$. In $70 \%$ of the cases there are multiple renal vessels with variable origin and drainage patterns. The challenges in laparoscopic nephrectomy of a HSK pertain to dealing with multiple vessels as well as disconnecting the kidney at the isthmus. The issue of multiple vessels and variable vascular patterns is well recognized and it calls for a meticulous delineation of the vascular anatomy both preoperatively and intraoperatively and taking control of these vessels appropriately during surgery $[10,11]$. However, the same kind of awareness regarding the anatomy of the isthmus during isthmectomy seems to be lacking. The reports of isthmectomy in the literature do not specify the type of isthmus that has been dealt with $[12,13]$. As pointed out earlier, about $60 \%$ of HSKs with lower polar fusion have L-shaped kidney with fusion happening well beyond the midline on the contralateral side. Reaching the point of fusion well beyond the midline during laparoscopy may not be easy and it may result in incomplete removal. If only a small stump of a parenchymatous isthmus is left behind it may not be of any consequence. However, if that parenchymatous stump was also to contain a small portion collecting system within, then urinary leak is a potential possibility. In our case the HSK was L-shaped with the lower pole of the right kidney reaching well beyond the midline to fuse with the lower pole of the left kidney lateral to the aorta. The point of fusion was just a linear line. The kidney was grossly hydronephrotic with the dilated calices eroding the parenchyma and reaching up to the edge of the kidney and fairly close to the point of fusion. But this anatomy was somehow not appreciated in the first CT-Urogram prior to laparoscopic nephrectomy. Even though the isthmus was divided medial to the IVC, it still left behind a small stump of parenchyma with its contained collecting system. This led to a persistent urinary leak. This adverse outcome in our case could have been averted by clearly identifying the type of fusion and the anatomy of the isthmus in the preoperative imaging. In case of any uncertainty in the preoperative imaging, retrograde pyelography prior to nephrectomy would have clarified the relationship of pelvicalyceal system and the isthmus and how far medially the PCS was extending. This knowledge would have helped in avoiding cutting through the collecting system when dividing the isthmus. Moreover, if the point of division of the isthmus has to be beyond the lateral side of the contralateral great vessel, then laparoscopic approach may be extremely difficult and an open surgery may be a better option to prevent any incomplete removal.

\section{Conflicts of Interest}

The authors declare that they have no conflicts of interest.

\section{References}

[1] S. Strauss, T. Dushnitsky, A. Peer, H. Manor, E. Libson, and P. D. Lebensart, "Sonographic features of horseshoe kidney: Review of 34 patients," Journal of Ultrasound in Medicine, vol. 19, no. 1, pp. 27-31, 2000.
[2] B.-K. Je, H. K. Kyung, and P. S. Horn, "Incidence and spectrum of renal complications and extrarenal diseases and syndromes in 380 children and young adults with horseshoe kidney," American Journal of Roentgenology, vol. 205, no. 6, pp. 13061314, 2015.

[3] A. Z. Weizer, A. D. Silverstein, B. K. Auge et al., "Determining the incidence of horseshoe kidney from radiographic data at a single institution," The Journal of Urology, vol. 170, no. 5, pp. 1722-1726, 2003.

[4] A. C. Allen, The Kidney: Medical and Surgical Diseases, Grune \& Stratton, New York, NY, USA, 1951.

[5] P. H. Tan, G. S. Chiang, and A. H. Tay, "Pathology of urinary tract malformations in a paediatric autopsy series," ANNALS Academy of Medicine Singapore, vol. 23, pp. 838-843, 1994.

[6] E. F. Nation, "Horseshoe kidney: a study of thirty-two autopsy and nine surgical cases," The Journal of Urology, vol. 53, no. 6, pp. 762-768, 1945.

[7] B. Glodny, J. Petersen, K. J. Hofmann et al., "Kidney fusion anomalies revisited: clinical and radiological analysis of 209 cases of crossed fused ectopia and horseshoe kidney," $B J U$ International, vol. 103, no. 2, pp. 224-235, 2009.

[8] K. Taghavi, J. Kirkpatrick, and S. A. Mirjalili, “The horseshoe kidney: Surgical anatomy and embryology," Journal of Pediatric Urology, vol. 12, no. 5, pp. 275-280, 2016.

[9] O. B. Stroosma, M. R. Scheltinga, B. M. Stubenitsky, and G. Kootstra, "Horseshoe kidney transplantation: An overview," Clinical Transplantation, vol. 14, no. 6, pp. 515-519, 2000.

[10] O. Olsson and M. Wholey, "Vascular abnormalities in gross anomalies of kidneys," Acta Radiologica, vol. 2, no. 5, pp. 420432, 1964.

[11] L. Fazio, H. Razvi, and J. L. Chin, "Malignancy in horseshoe kidneys: review and discussion of surgical implications," The Canadian Journal of Urology, vol. 10, pp. 1899-1904, 2003 (Chinese).

[12] P. Jarzemski and S. Listopadzki, "Laparoscopic horseshoe kidney isthmusectomy: Four case reports," Wideochirurgia $i$ Inne Techniki Maloinwazyjne, vol. 9, no. 1, pp. 115-120, 2014.

[13] A. Khan, A. Myatt, V. Palit, C. S. Biyani, and D. Urol, "Laparoscopic heminephrectomy of a horseshoe kidney," Journal of the Society of Laparoendoscopic Surgeons, vol. 15, no. 3, pp. 415-420, 2011. 


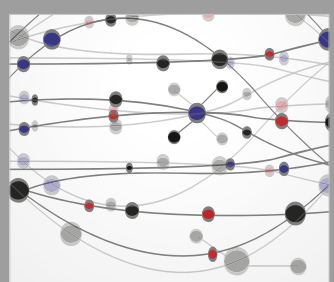

The Scientific World Journal
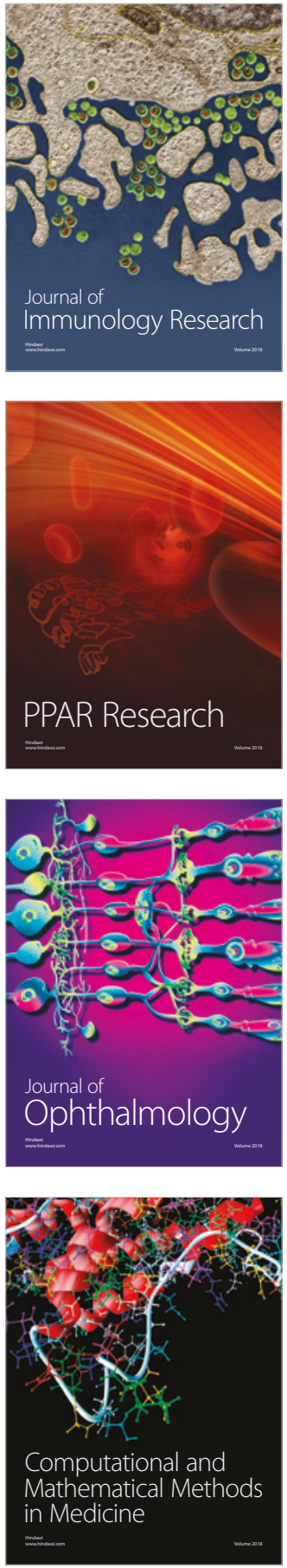

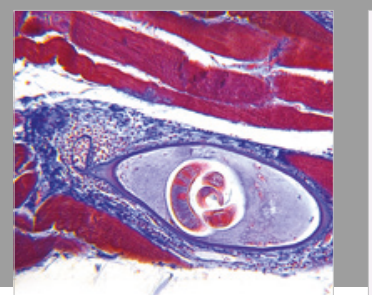

Gastroenterology Research and Practice

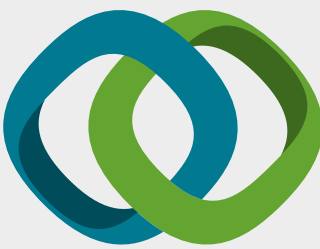

\section{Hindawi}

Submit your manuscripts at

www.hindawi.com
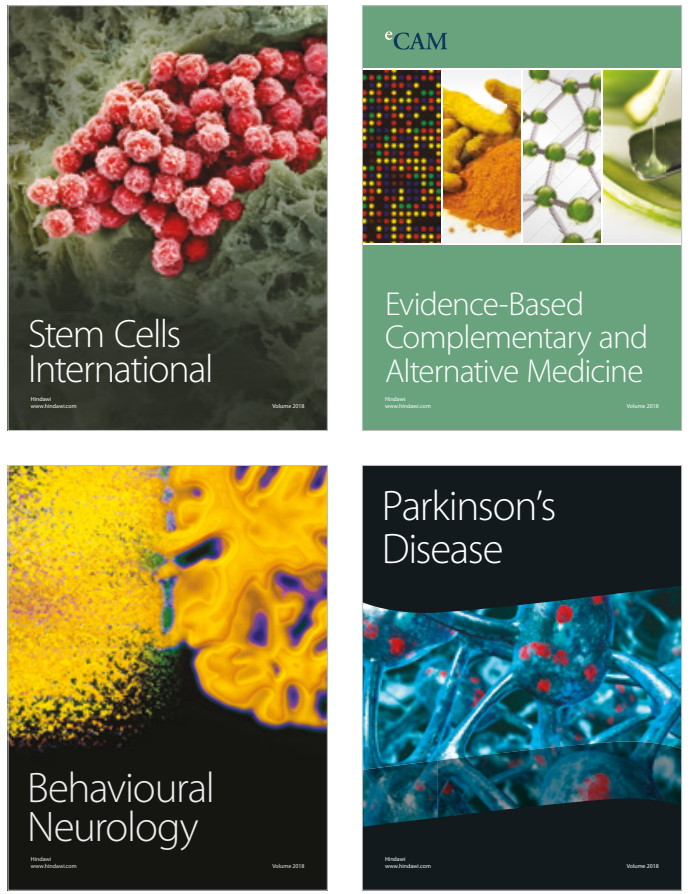

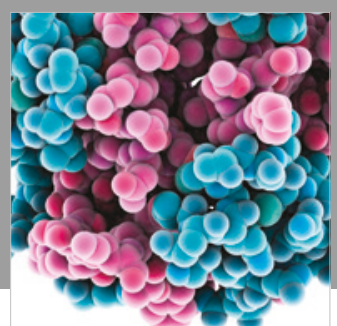

ournal of

Diabetes Research

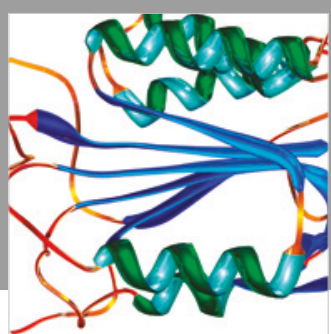

Disease Markers
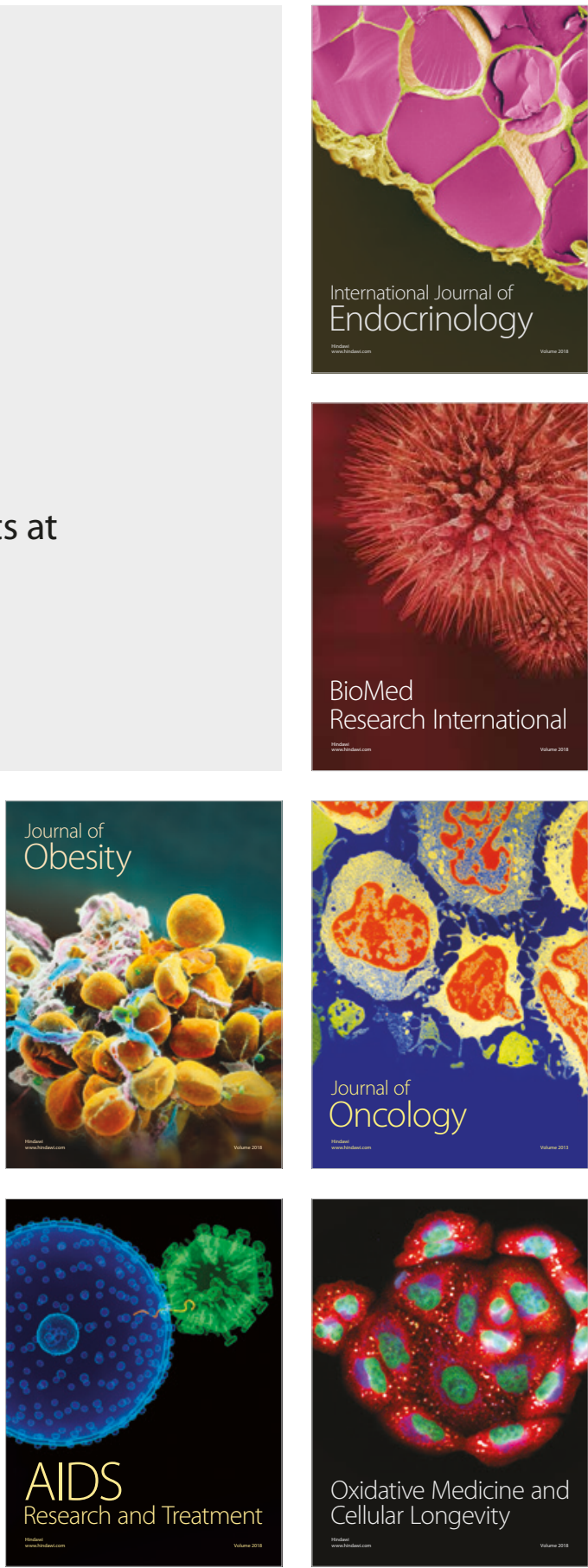